\title{
Role of Oxygen Radicals Generated by NADPH Oxidase in Apoptosis Induced in Human Leukemia Cells
}

\author{
Wakako Hiraoka, ${ }^{\star}$ Nancy Vazquez, ${ }^{\ddagger}$ Wilberto Nieves-Neira, ${ }^{\star}$ Stephen J. Chanock, ${ }^{\ddagger}$ and Yves Pommier* \\ $*$ Laboratory of Molecular Pharmacology, and ${ }^{\ddagger}$ Pediatric Oncology Branch, National Cancer Institute, Bethesda, Maryland 20892
}

\begin{abstract}
We have used a human leukemia cell line that, after homologous recombination knockout of the gp91-phox subunit of the phagocyte respiratory-burst oxidase cytochrome $b-558$, mimics chronic granulomatous disease (X-CGD) to study the role of oxygen radicals in apoptosis. Camptothecin (CPT), a topoisomerase I inhibitor, induced significantly more apoptosis in PLB-985 cells than in X-CGD cells. Sensitivity to CPT was enhanced after neutrophilic differentiation, but was lost after monocytic differentiation. No difference between the two cell lines was observed after treatment with other apoptosis inducers, including etoposide, ultraviolet radiation, ionizing radiation, hydrogen peroxide, or 7-hydroxystaurosporine. After granulocytic differentiation of both cell lines, CPT still induced apoptosis, suggesting independence from replication in fully differentiated and growth-arrested cells. Pyrrolidine dithiocarbamate (an antioxidant inhibitor of NF- $\mathrm{NB}$ ) and catalase partially inhibited CPT-induced DNA fragmentation in granulocytic-differentiated PLB-985 cells, but had no effect in X-CGD cells. Flow cytometry analysis revealed that reactive oxygen intermediates were generated in CPT-treated PLB-985 cells. These data indicate that oxygen radicals generated by NADPH oxidase may contribute directly or indirectly to CPT-induced apoptosis in human leukemia and in neutrophilic-differentiated cells. (J. Clin. Invest. 1998. 102:1961-1968.) Key words: NADPH oxidase $\cdot$ chronic granulomatous disease $\cdot$ reactive oxygen intermediates $\bullet$ apoptosis $\bullet$ camptothecin
\end{abstract}

\section{Introduction}

Apoptosis, programmed cell death, is essential to develop and maintain homeostasis during embryogenesis, cell growth, and elimination of damaged cells in eukaryotic organisms. Insights into the pathways that regulate apoptosis have been informative in elucidating basic processes of cell differentiation and death. The dysregulation of apoptotic pathways has been fruitful in understanding the pathogenesis of a spectrum of diseases, including degenerative, autoimmune, and neoplastic disorders (1). The generation of reactive oxygen intermediates

\footnotetext{
Address correspondence to Yves Pommier, Laboratory of Molecular Pharmacology, Division of Basic Sciences, National Cancer Institute, Building 37, Room 5D02, National Institutes of Health, Bethesda, MD 20892-4255. Phone: 301-496-5944; FAX: 301-402-0752; E-mail: pommier@nih.gov

Received for publication 16 March 1998 and accepted in revised form 5 October 1998.
}

The Journal of Clinical Investigation

Volume 102, Number 11, December 1998, 1961-1968

http://www.jci.org
$(\mathrm{ROIs})^{1}$ is indispensable for signal transduction and microbicidal pathways, but at the same time may also be harmful to the cell under aerobic conditions (2-6). Recently, it has been proposed that ROIs may play a critical role in regulating apoptosis. ROIs are free radicals, such as hydroxyl radicals $(\mathrm{OH} \bullet)$, and also some nonradical derivatives, such as hydrogen peroxide $\left(\mathrm{H}_{2} \mathrm{O}_{2}\right)$ and superoxide anion $\left(\mathrm{O}_{2}^{-}\right)$. An important source of ROIs common to all cells is the mitochondrial electron transport system. Schulze-Osthoff et al. showed that ROIs generated by mitochondria can contribute to TNF-induced cell killing in mouse fibrosarcoma cells (7). Other reports also clarified the function of mitochondrial oxidase during apoptosis induced by ceramide and dexamethazone $(8,9)$.

The most important system for ROIs generation in phagocytic cells is the nicotinamide adenine dinucleotide phosphate (NADPH) oxidase. Recently, several reports have suggested that the phagocyte NADPH oxidase may contribute to the induction of apoptosis in leukocytes $(10,11)$. The respiratory burst oxidase, also known as the phagocyte NADPH oxidase, catalyzes the NADPH-dependent reduction of oxygen to $\mathrm{O}_{2}^{-}$, which in turn leads to the production of secondary derivatives such as $\mathrm{OH} \bullet$ and $\mathrm{H}_{2} \mathrm{O}_{2}$. These radicals are critical for oxygendependent antimicrobial defense against a wide range of intra- and extracellular pathogens (12-15). Components of this oxidase include the cytochrome $b$-558, a membrane-bound flavohemoprotein comprised of two subunits, gp91-phox and p22-phox, and cytosolic proteins, p47-phox, p67-phox, and p40-phox, and the small GTP-binding proteins, Rac1 or Rac2. Assembly of the cytosolic components with the membranebound flavohemoprotein at the cell membrane is necessary to form an active complex upon stimulation $(16,17)$. Congenital absence of one or more of the following components of the NADPH oxidase, gp91-phox, p47-phox, p67-phox, or p22phox, leads to chronic granulomatous disease (CGD), a disorder of the host defense system (15). CGD is characterized by recurrent and life-threatening infections and chronic formation of granulomas. Several recent reports have suggested that the synthesis of gp91-phox and association with the other component of the heterodimer, p22-phox, is important in the maturation of phagocytic cells $(18,19)$.

A cell line, X-CGD, has been reported in which the gp91phox gene was disrupted by homologous recombination in the human leukemia cell line, PLB-985 (18). PLB-985 and X-CGD, which differ only by the disruption of the gp91-phox gene, have biphenotypic potential for differentiation to neutrophils or monocytes. Thus, the two cell lines offer an excellent in vitro model for investigating the potential role of the NADPH

1. Abbreviations used in this paper: CPT, camptothecin; DMF, dimethylformamide; MFI, mean fluorescence intensity; NADPH, nicotinamide adenine dinucleotide phosphate; ROIs, reactive oxygen intermediates; top1, topoisomerase I; UCN-01, 7-hydroxystaurosporine; VP-16, etoposide; X-CGD, X-chromosome linked chronic granulomatous disease. 
oxidase in apoptosis in phagocytic cells. We compared the induction of apoptotic DNA fragmentation in X-CGD cells and its parent PLB-985 cells. A selection of inducers of apoptosis were used to investigate the potential for ROIs to participate in one or more specific apoptotic pathways. These included exogenous ROI sources, $\gamma$-rays and $\mathrm{H}_{2} \mathrm{O}_{2}$, ultraviolet (UV) radiation, the protein kinase $\mathrm{C}$ inhibitor 7-hydroxystaurosporine (UCN-01) (20-22), and the topoisomerase inhibitors camptothecin (CPT) (23) and etoposide (VP-16) (24).

\section{Methods}

Chemicals. CPT was a gift from Drs. M.E. Wall and M.C. Wani (Research Triangle Institute, Research Triangle Park, NC). VP-16 was a gift from Bristol-Myers-Squibb Laboratories (Wallingford, CT). UCN-01 was provided by Dr. H. Nakano (Kyowa Hakko Co., Tokyo, Japan) or the Drug Synthesis Chemistry Branch, Division of Cancer Treatment, National Cancer Institute (Bethesda, MD). All agents were dissolved in DMSO at $10 \mathrm{mM}$, aliquoted, frozen, and diluted further in water immediately prior to each experiment. $\left[2-{ }^{14} \mathrm{C}\right]$ thymidine $(2.2$ $\mathrm{GBq} / \mathrm{mmol}$ ) was purchased from New England Nuclear (Boston, MA). All other chemicals were reagent grade and purchased from either Sigma Chemical Co. (St. Louis, MO) or other local sources.

Cell culture and differentiation. Human myelomonoblastic cell line PLB-985 cells were a gift from Dr. P. Newburger (University of Massachusetts, Worcester, MA). X-CGD cells were prepared from PLB985 cells after disruption of the $\mathrm{X}$ chromosome-linked gp91-phox gene (18). Cells were cultured at $37^{\circ} \mathrm{C}$ in a $5 \% \mathrm{CO}_{2}$ atmosphere, in RPMI 1640 complete medium (GIBCO BRL, Grand Island, NY) supplemented with $2 \mathrm{mM}$ glutamine, $100 \mathrm{U} / \mathrm{ml}$ penicillin, and $100 \mu \mathrm{g} / \mathrm{ml}$ streptomycin plus $10 \%$ FBS (Atlanta Biologicals, Norcross, GA). For neutrophilic differentiation, logarithmically growing cells $\left(5 \times 10^{5} / \mathrm{ml}\right)$ were incubated with $10 \mu \mathrm{M}$ 9-cis-retinoic acid (RA) for $24 \mathrm{~h}$, and then by incubation with $0.5 \%$ dimethylformamide (DMF) for $4 \mathrm{~d}$. Under these conditions, PLB-985 cells acquired brisk respiratory burst activity, as assayed by the nitro blue tetrazolium test. For monocytic differentiation, logarithmically growing cells $\left(5 \times 10^{5} / \mathrm{ml}\right)$ were exposed to $50 \mathrm{nM}$ PMA for $5 \mathrm{~d}$. After $5 \mathrm{~d}$ of monocytic differentiation, PLB-985 cells exhibited brisk respiratory burst activity. In addition, both PLB-985 cells and X-CGD cells became adherent.

Detection of DNA fragmentation. DNA fragmentation related to apoptosis was measured by filter-elution assay as described previously $(24,25)$. Briefly, each sample was loaded onto a protein-absorbing filter (vinyl/acrylic copolymers filters, Metricel, $0.8 \mu \mathrm{m}$ pore size, 25-mm diameter; Gelman Sciences, Inc., Ann Arbor, MI). Filters were washed with $5 \mathrm{ml}$ of HBSS and lysed with $5 \mathrm{ml}$ of LS-10 solution (0.2\% sodium sarkosyl, $2 \mathrm{M} \mathrm{NaCl}, 0.04 \mathrm{M}$ EDTA, $\mathrm{pH} 10.0)$. After the lysis had dripped through by gravity, filters and lysates were washed with $5 \mathrm{ml}$ of $0.02 \mathrm{~N} \mathrm{Na}_{2}$ EDTA ( $\mathrm{pH} 10.0$ ). The cell deposition medium and wash with HBSS $(W)$, lysis samples $(L)$, EDTA samples $(E)$, and filter samples $(F)$ were collected and counted by liquid scintillation (26). DNA fragmentation was calculated as the DNA eluting from the filter as:

DNA fragmentation $(F)=(W+L+E) /(W+L+E+F)$.

Results were expressed as the percentage of DNA fragmentation in treated cells compared with DNA fragmented in control untreated cells (background) using the formula:

$\%$ DNA fragmentation $=\left(F-F_{0} / 1-F_{0}\right) \times 100$

where $F$ and $F_{0}$ represent DNA fragmentation in treated and control cells, respectively.

Morphological change. 1,000,000 cells were harvested and washed with $1 \times$ PBS after drug treatment. Cells were fixed in $1 \%$ paraformaldehyde for 15 min on ice, washed with PBS, and resuspended in
$70 \%$ ethanol. Cells were kept at $-20^{\circ} \mathrm{C}$ overnight. After removal of the ethanol by centrifugation, the cells were resuspended in PBS and stained with $2 \mu \mathrm{g} / \mathrm{ml} \mathrm{4}$, 6 -diamidino-2-phenylindole, dihydrochloride (DAPI) for $30 \mathrm{~min}$ at $37^{\circ} \mathrm{C}$ in the dark. After washing with PBS, the cells were observed with a fluorescence microscope using a mercury lamp with excitation and emission settings of $365 \mathrm{~nm}$ and $430 \mathrm{~nm}$, respectively.

Apoptosis detection with annexin V-FITC. The annexin V-FITC apoptosis detection kit was purchased from Oncogene Research Products (Cambridge, MA). 1,000,000 cells were washed with PBS and then incubated with $0.5 \mu \mathrm{g} / \mathrm{ml}$ annexin V-FITC in $0.5 \mathrm{ml}$ of cold binding buffer for $15 \mathrm{~min}$ at room temperature. Cells were centrifuged at $1,000 \mathrm{~g}$ for $5 \mathrm{~min}$ at room temperature, and supernatant was removed. Cells were resuspended in $0.5 \mathrm{ml}$ of cold binding buffer, and propidium iodide was added at the concentration of $0.6 \mu \mathrm{g} / \mathrm{ml}$. FACS analysis was performed immediately after staining.

Western blot analysis. Monoclonal mouse anti-human topoisomerase I (top1) was obtained from Dr. Yung-Chi Cheng (Yale University, New Haven, CT). Anti-proliferating cell nuclear antigen mouse mAb was purchased from Santa Cruz Biotechnology (Santa Cruz, CA). Cells were harvested and washed with ice-cold PBS. The cell pellets were lysed with $3 \times$ loading buffer $(0.195 \mathrm{M}$ Tris- $\mathrm{HCl}, \mathrm{pH} 6.8$, $30 \%$ glycerol, $9 \%$ SDS, $0.075 \%$ bromophenol blue, $0.2 \mathrm{M}$ dithiothreitol). The lysates were kept on ice for $30 \mathrm{~min}$ and then centrifuged $\left(12,000 \mathrm{rpm}\right.$ for $30 \mathrm{~min}$ at $\left.4^{\circ} \mathrm{C}\right)$. The resulting supernatants were used for immunoblot. For protein determination, the cells were lysed in the loading buffer without bromophenol blue and dithiothreitol. Protein determination was performed using a protein assay kit according to the manufacturer's instructions (Bio-Rad, Melville, NY). $50 \mu \mathrm{g}$ of total protein was separated on a precast $10 \%$ polyacrylamide Trisglycine gel (NOVEX, San Diego, CA). After electrophoresis, proteins were transferred to Immobilon membranes (Millipore, Bedford, MA) for $2 \mathrm{~h}$ at $100 \mathrm{~V}$. Membranes were blocked for $1 \mathrm{~h}$ in Tris-buffered saline with $0.1 \%$ Tween-20 (TBS-T) containing 5\% nonfat dry milk. Membranes were then probed overnight at $4^{\circ} \mathrm{C}$ with anti-human mouse mAb (1:1,000 dilution in TBS-T) followed by $1 \mathrm{~h}$ with antimouse Ig horseradish peroxidase-conjugate (Amersham Life Science, Arlington Heights, IL) (1:1,000 dilution in TBS-T). Proteins were visualized by enhanced chemiluminescence (Pierce, Rockford, IL) according to the manufacturer's instructions.

Measurement of ROIs. Generation of reactive oxygen species was measured using $2^{\prime}, 7^{\prime}$-dichlorodihydrofluorescein diacetate $\left(\mathrm{H}_{2}-\right.$ DCFHDA; Molecular Probes, Inc., Eugene, OR) (27). This cell-permeable probe is hydrolyzed to a fluorescent derivative in cells and, upon reaction with peroxide, the fluorescence of this agent is significantly increased. Cells were incubated with $5 \mu \mathrm{M} \mathrm{H}_{2}$ DCFHDA for 30 min at $37^{\circ} \mathrm{C}$, then treated with CPT for $1 \mathrm{~h}$. The harvested cells were immediately analyzed by a FACScan flow cytometer (Becton Dickinson, Mountain View, CA) with excitation and emission settings of 488 $\mathrm{nm}$ and $530 \mathrm{~nm}$, respectively. The intensity of fluorescence of each sample was expressed as mean fluorescence intensity (MFI) calculated from each peak. The extent of ROIs production was indicated as the difference between $\log M F I_{\text {drug }}$ and $\log M F I_{\text {control }}\left(M F I_{\text {drug }}\right.$ is the MFI of CPT-treated cells, $M F I_{\text {control }}$ is the MFI of control cells).

Statistical analysis. Data are expressed as mean \pm SD. Differences between data sets were evaluated by performing a unpaired Student's $t$ test. A level of $P<0.05$ was accepted as statistically significant.

\section{Results}

DNA fragmentation produced by apoptosis inducers in X-CGD and PLB-985 cells. Logarithmically growing X-CGD and PLB985 cells were exposed to various apoptosis inducers, and DNA fragmentation was measured by filter-elution assay $(25,28)$ (Fig. 1), which can detect both oligonucleosomes and large DNA fragments ( $<20-50 \mathrm{kbp}$; Shao, R.G., and Y. Pommier, unpublished data). Treatment with CPT (top1 inhibitor), VP-16 
(top2 inhibitor) or UCN-01 (protein kinase C inhibitor) was for $6 \mathrm{~h}$ in complete medium before the DNA fragmentation assays. For $\mathrm{H}_{2} \mathrm{O}_{2}$, the cells were exposed in HBSS for $1 \mathrm{~h}$ and further incubated in fresh medium for $12 \mathrm{~h}$. For UV radiation, cells were resuspended in HBSS without phenol red within 30 min prior to the irradiation. After UV irradiation, the HBSS was replaced by fresh medium, and the cells were incubated for $12 \mathrm{~h}$ before the DNA fragmentation assays. $\gamma$-irradiated cells were assayed $72 \mathrm{~h}$ after irradiation. Fig. 1 showed that CPT-treated X-CGD cells produced less DNA fragmentation than PLB-985 cells. However, for the other inducers of apoptosis, there was no appreciable difference between the X-CGD and PLB-985 cell lines. Only in response to CPT was the measured DNA fragmentation greater in the NADPH-competent cells than in null cells. These results indicate that a functional NADPH oxidase in phagocytic cells is not required for DNA fragmentation induced by the topoisomerase II poison, VP-16, UV radiation, ionizing radiation, $\mathrm{H}_{2} \mathrm{O}_{2}$, or UCN-01.

Fig. 2 shows the morphological changes of cells treated with CPT. The nuclear changes were typical of apoptosis in both cell lines. Scoring cells for apoptotic morphology indicated a good correlation between percentage of apoptotic cells and DNA fragmentation. For instance, the percentage of apoptotic cells assessed morphologically after treatment with $10 \mu \mathrm{M}$ CPT for $6 \mathrm{~h}$ was $50 \pm 1 \%$ for PLB-985 cells versus $58 \pm 1 \%$ for $\mathrm{X}-\mathrm{CGD}$ cells. These numbers are comparable with the percentage of DNA fragmentation detected by filter elution assay (Fig. $1 \mathrm{~A}$ ), which suggests that the DNA filter elution assay measures the fraction of apoptotic cells. Additional experiments using dual labeling with annexin $\mathrm{V}$ and propidium iodide indicated that annexin $\mathrm{V}$-positive cells corresponded to $\sim 50 \%$ of the cells and that the annexin $\mathrm{V}$-positive cells were also positive for propidium iodide (Fig. 3). Together these data
A

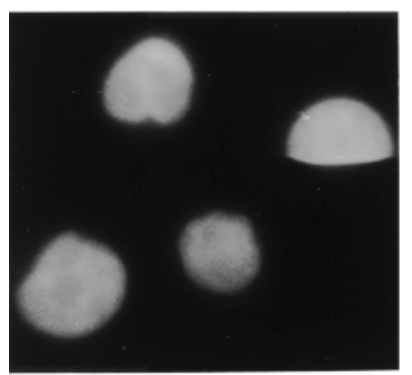

C

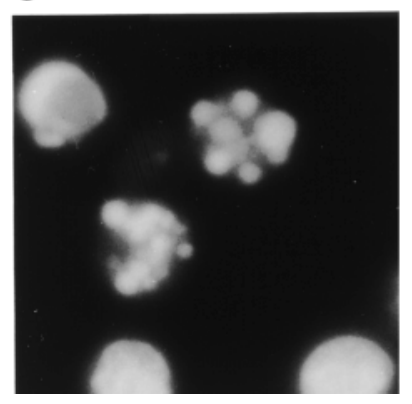

B

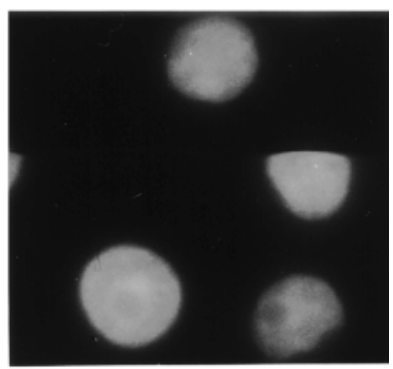

D

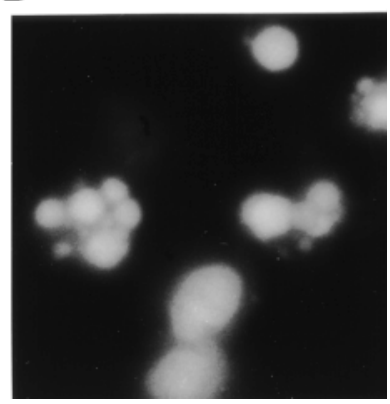

Figure 2. Morphological changes in cells treated with CPT. Cells were stained with DAPI. Upper panels show untreated X-CGD $(A)$ and PLB-985 cells $(B)$. Lower panels show X-CGD $(C)$ and PLB-985 cells $(D)$ treated with $5 \mu \mathrm{M}$ CPT for $6 \mathrm{~h}$.

indicate that CPT-induced DNA fragmentation reflects the fraction of apoptotic cells.

Differential induction of apoptosis by CPT in granulocyticdifferentiated and monocytic-differentiated cells. To obtain fur-
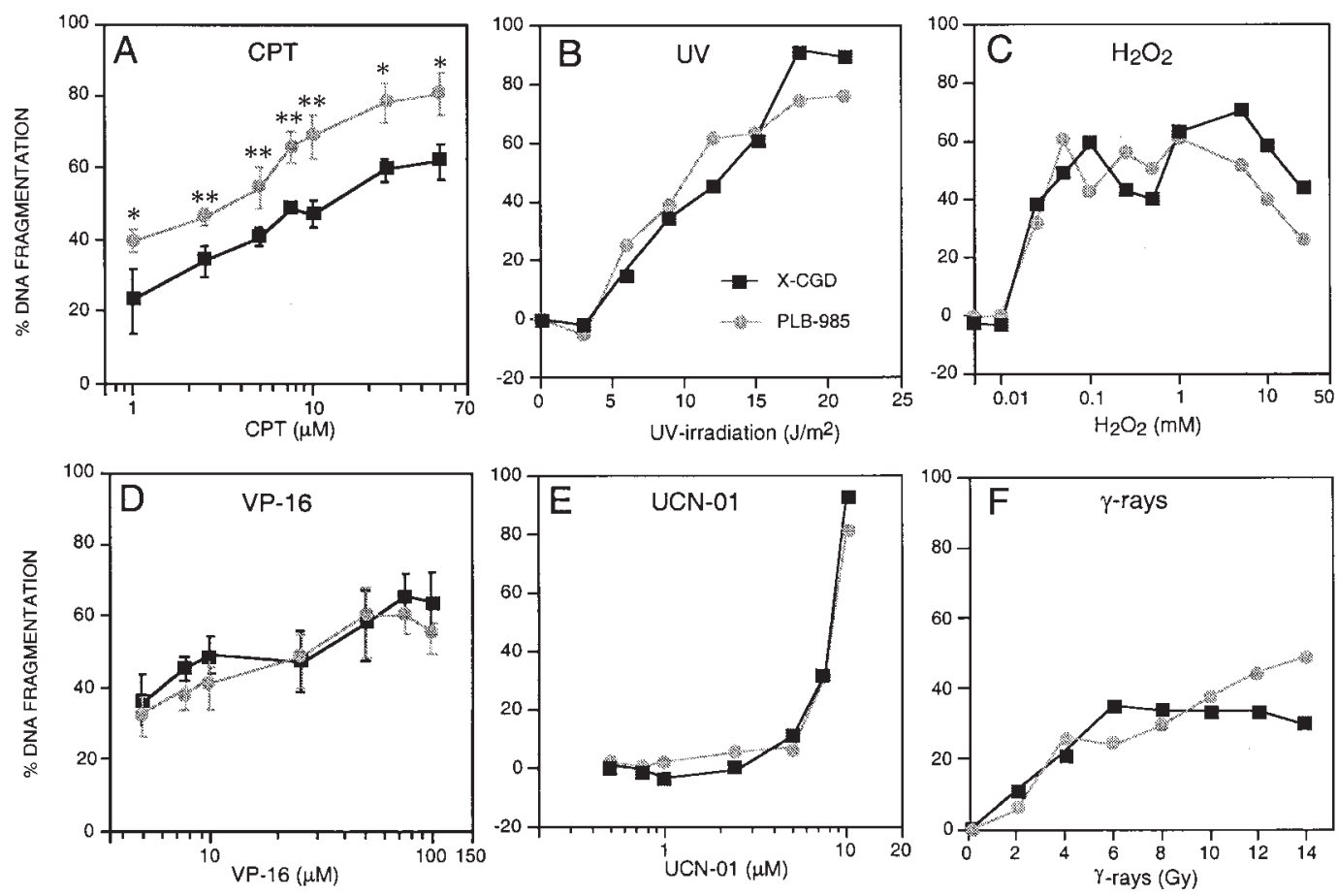

Figure 1. Induction of apoptotic DNA fragmentation in PLB-985 (gray circles) and X-CGD cells (filled squares). Cells were treated with CPT, VP-16, or UCN-01 for $6 \mathrm{~h}$ before being assayed for DNA fragmentation by filter elution. UV-irradiated cells were incubated for $12 \mathrm{~h}$ before being assayed for DNA fragmentation. $\mathrm{H}_{2} \mathrm{O}_{2}$ treatments were for $30 \mathrm{~min}$, after which cells were incubated for $12 \mathrm{~h}$ before being assayed for DNA fragmentation. $\gamma$-irradiated cells were incubated for $72 \mathrm{~h}$ before being assayed for DNA fragmentation. Data in $A$ and $D$ are the means \pm SD obtained from four independent experiments $(* P<0.05$, $* * P<0.01)$. Data in $B, C$, $E$, and $F$ are from representative experiments that were reproduced independently. 

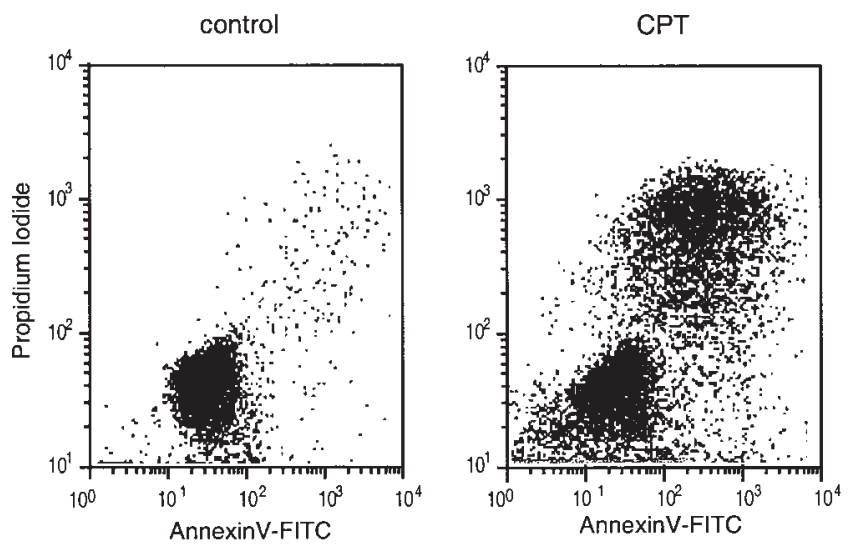

Figure 3. Apoptosis detection with annexin V-FITC in CPT-treated cells. PLB-985 cells were treated as indicated above each panel. Cells conjugated with annexin V-FITC and stained with propidium iodide were analyzed by flow cytometry. Control viable cells (left panel) did not bind annexin V-FITC or propidium iodide as reflected in the lower left-hand quadrant of the dot plot. Both annexin V-FITC and propidium iodide positive cells were increased after incubation with $10 \mu \mathrm{M}$ CPT for $6 \mathrm{~h}$ (right panel).

ther information about the possible role of NADPH oxidase in the induction of CPT-induced apoptosis, we repeated the DNA fragmentation experiments under differentiation conditions. PLB-985 myeloblastoma cells are known to differentiate into granulocytic cells after treatment combination with RA and DMF, and into monocytic cell lines after treatment with PMA. In the course of differentiation, the expression of NADPH components is significantly increased for gp91-phox, p47-phox, and p67-phox, which leads to the ability to generate more ROIs (19). Thus, if CPT-induced apoptosis is related to NADPH oxidase function, the extent of DNA fragmentation induced by NADPH oxidase would be expected to increase in CPT-treated cells after differentiation. CPT or VP-16 treatments and DNA fragmentation assays were performed $5 \mathrm{~d}$ after initiation of the differentiation treatments (Fig. 4). A significant difference between X-CGD and PLB-985 cells in the production of DNA fragmentation was observed in CPTtreated granulocytic cells (Fig. $4 \mathrm{~B}$ ). The observed difference that increased between the X-CGD and PLB-985 cells appeared to be greater in the granulocyte-differentiated than in the undifferentiated cells. These results suggest the possibility of a specific role of NADPH-dependent oxygen radicals in CPT-induced apoptosis. VP-16-induced DNA fragmentation was markedly less in granulocytic-differentiated cells than in undifferentiated cells, and the difference between the X-CGD and PLB-985 cells was not significant in granulocytic-differentiated cells. In the case of monocytic differentiated cells, CPTor VP-16-induced DNA fragmentation was strongly attenuated for both CPT and VP-16 compared with undifferentiated cells.

Expression of top1 in X-CGD and PLB-985 cells before and after differentiation. The cellular effects of CPT in different cell lines is commonly attributable to differences in top1 protein levels (29). The greater the top1 level, the more top1mediated DNA damage is observed, which in turn is highly associated with enhanced cytotoxicity (23). Thus, a possible reason for the differential response of X-CGD and PLB-985 to CPT could be related to differences in top1 protein levels. Examination of top1 expression using Western blotting in X-CGD and PLB-985 cells showed that top1 protein levels were comparable in untreated X-CGD and PLB-985 cells (Fig. 5). After granulocytic and monocytic differentiation, there was no sig-
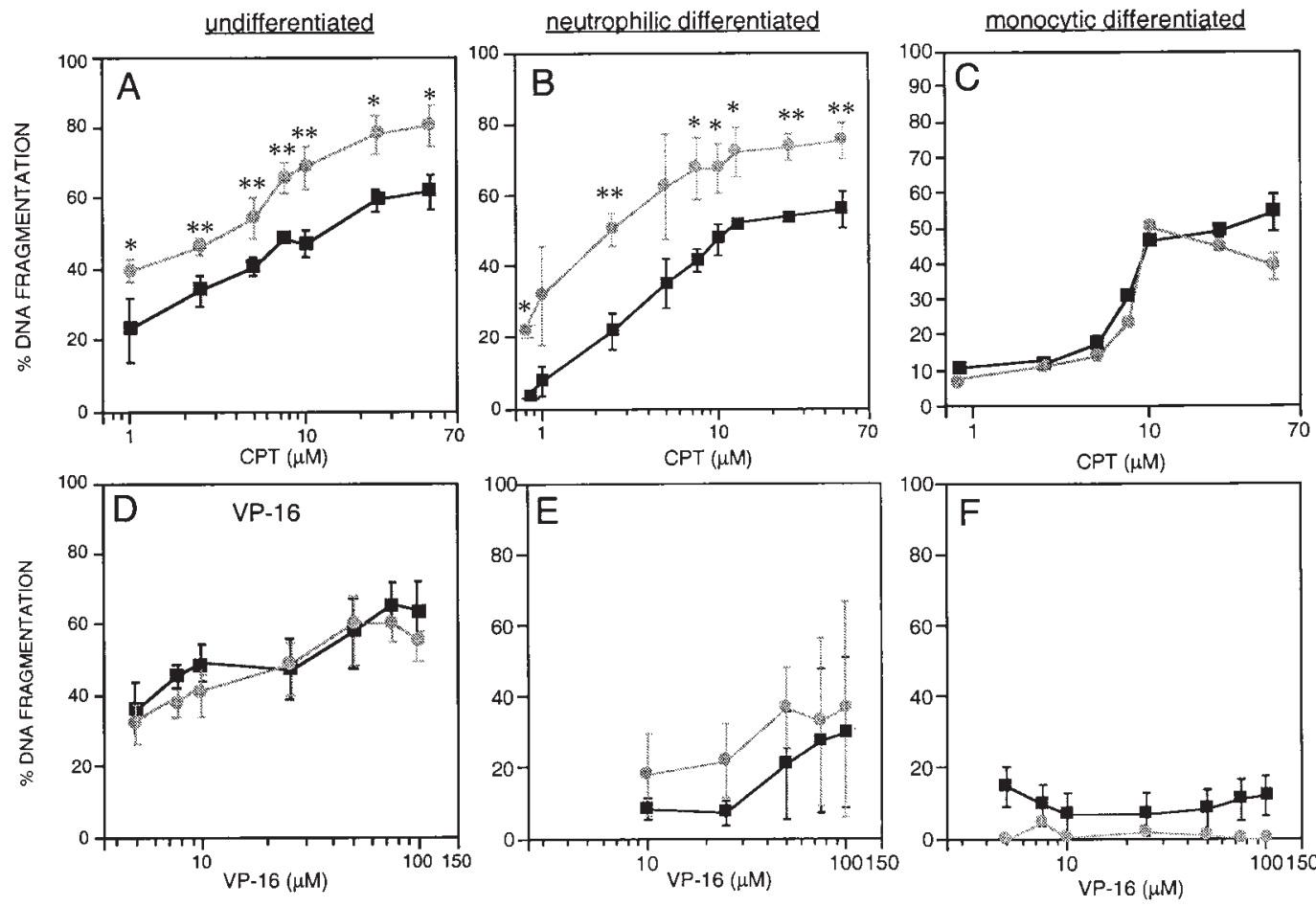

Figure 4. Effects of differentiating treatments on DNA fragmentation induced by topoisomerase inhibitors in PLB-985 (gray circles) and X-CGD (filled squares) cells.

Cells were incubated with CPT or VP-16 for $6 \mathrm{~h}$ before being assayed for DNA fragmentation. For neutrophilic differentiation $(B$ and $E)$, logarithmically growing cells $(5 \times$ $10^{5} / \mathrm{ml}$ ) were incubated with $10 \mu$ M RA. After $24 \mathrm{~h}$, $0.5 \%$ DMF was added to the medium and the cells were incubated for four additional days. For monocytic differentiation $(C$ and $F$ ), logarithmically growing cells $\left(5 \times 10^{5} / \mathrm{ml}\right)$ were exposed to $50 \mathrm{nM}$ PMA for $5 \mathrm{~d}$. Data are expressed as the mean \pm SD obtained from four independent experiments. $* P<0.05$, $* * P<0.01$. 


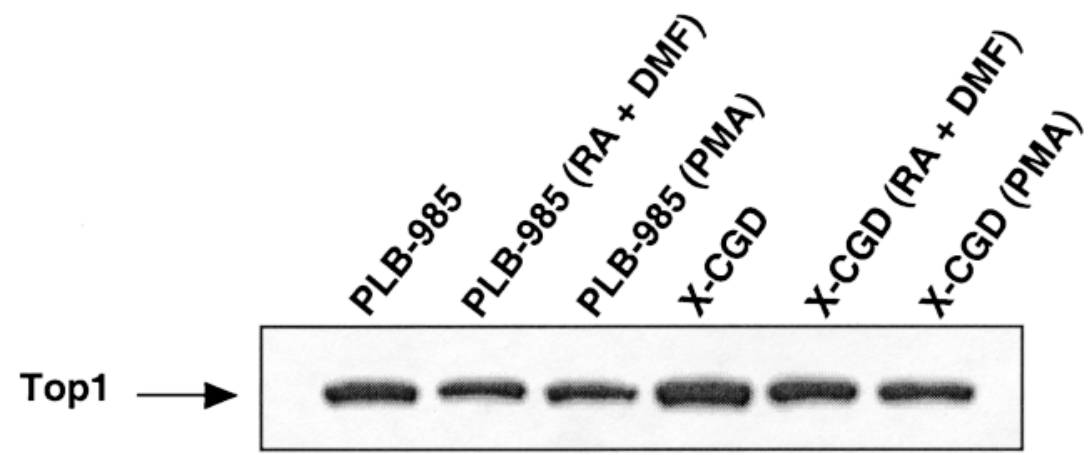

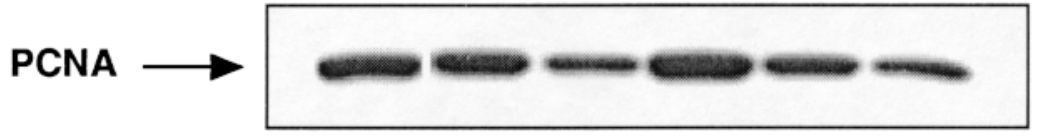

Figure 5. Top1 expression in PLB-985 and $\mathrm{X}$-CGD cells. Top1 levels were detected by Western blotting before and after differentiation. For neutrophilic differentiation, cells were incubated with $10 \mu \mathrm{M}$ RA. After $24 \mathrm{~h}, 0.5 \% \mathrm{DMF}$ was added to the medium, and the cells were incubated for an additional $4 \mathrm{~d}$. For monocytic differentiation, cells were exposed to $50 \mathrm{nM}$ PMA for $5 \mathrm{~d}$. nificant difference in top1 protein levels between X-CGD and PLB-985 cells. These results suggest that the amount of top1 protein does not account for differences in sensitivity to CPT between the two cell lines.

Inhibition of CPT-induced apoptosis by pyrrolidine dithiocarbamate (PDTC). PDTC is an antioxidant that inhibits NF$\kappa \mathrm{B}(4,5)$. We examined whether PDTC affected CPT-induced apoptosis in granulocytic-differentiated X-CGD and PLB-985 cells. Treatment with PDTC was initiated $1 \mathrm{~h}$ prior to the CPT exposure and continued for the $6 \mathrm{~h}$ of CPT treatment. Fig. 6 shows that PDTC partially inhibited CPT-induced DNA fragmentation in granulocytic-differentiated PLB-985 cells. In X-CGD cells, DNA fragmentation was resistant to PDTC treatment. It is notable that the DNA fragmentation results with PLB-985 cells treated with CPT and PDTC were comparable to the DNA fragmentation results observed in CPTtreated X-CGD cells. This suggests that the mechanism of CPT-induced apoptosis requires at least two or more independent processes, one NADPH-oxidase dependent on PDTC and one insensitive to PDTC, not necessarily linked to the NADPH oxidase. The latter is present both in X-CGD and PLB-985 cells.

Detection of ROIs in CPT-treated granulocytic-differentiated cells. We directly measured ROI production by flow cytometry using an $\mathrm{H}_{2}$ DCFHDA-based technique. Fig. 7 shows that CPT induced peroxide production in granulocytic differentiated PLB-985 cells and that the generation of ROIs increased with the CPT concentration. By contrast, no significant peak shift was detectable in CPT-treated granulocytic X-CGD cells (Fig. 7). ROIs were also detectable in undifferentiated PLB-985 cells, but the amount of ROIs was significantly less than in granulocytic differentiated cells (the maximum difference between $\log M F I_{\text {drug }}$ and $\log M F I_{\text {control }}$ was $<0.3$ ) (data not shown). In CPT-treated granulocytic PLB-985 cells, generation of ROIs was detected within the first $3 \mathrm{~h}$ of the CPT treatment, while DNA fragmentation became detectable $4.5 \mathrm{~h}$ after the beginning of the treatment (Fig. 8). These results indicate that the generation of ROIs in CPT-treated granulocytic PLB-
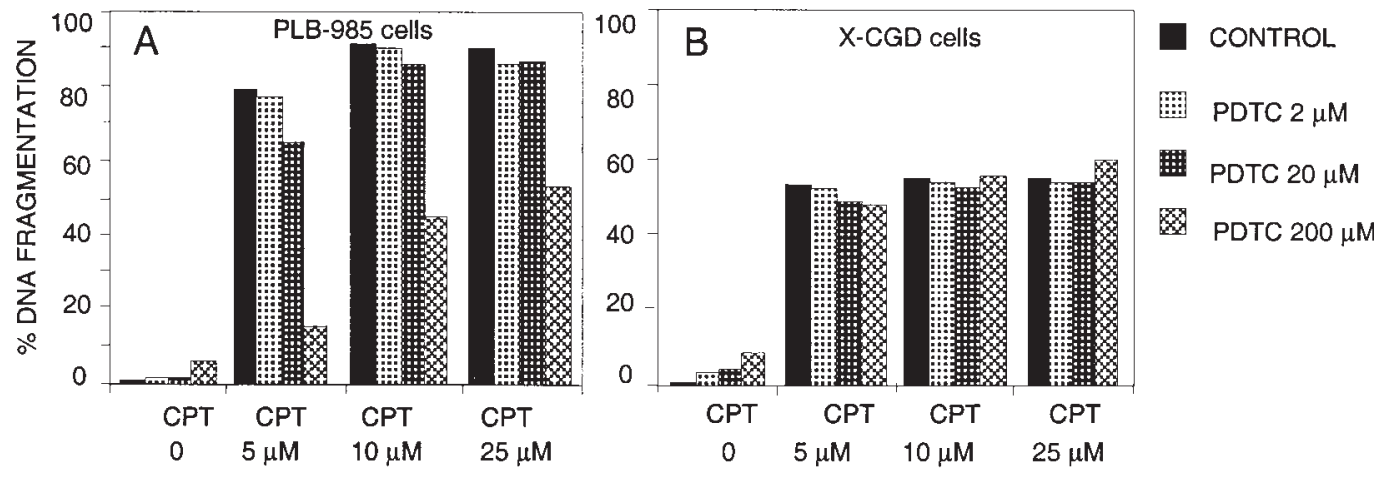

C Effects of antioxidant on CPT-induced DNA fragmentation

\begin{tabular}{lll} 
Drug & PLB-985 cells & X-CGD cells \\
\hline CPT & $76.9+0.16$ & $50.0+0.48$ \\
CPT + SOD & $81.7+4.17$ & $51.1+0.71$ \\
CPT + catalase & $57.1+0.51^{* *}$ & $47.7+0.89$
\end{tabular}

Figure 6. Effect of antioxidant on CPT-induced DNA fragmentation in PLB-985 and X-CGD cells after neutrophilic differentiation. Cells were preincubated with PDTC, SOD, or catalase for $1 \mathrm{~h}$, and then CPT was added to the medium. DNA fragmentation was measured $6 \mathrm{~h}$ later. $(A)$ PLB-985 cells. $(B)$ X-CGD cells. $(C)$ CPT concentration was 25 $\mu \mathrm{M}$; SOD and catalase concentrations were 50 $\mathrm{U} / \mathrm{ml}$ and $50 \mu \mathrm{g} / \mathrm{ml}$, respectively. Data are expressed as mean $\pm \mathrm{SD}$ obtained from four independent experiments. $* P<0.01$. 

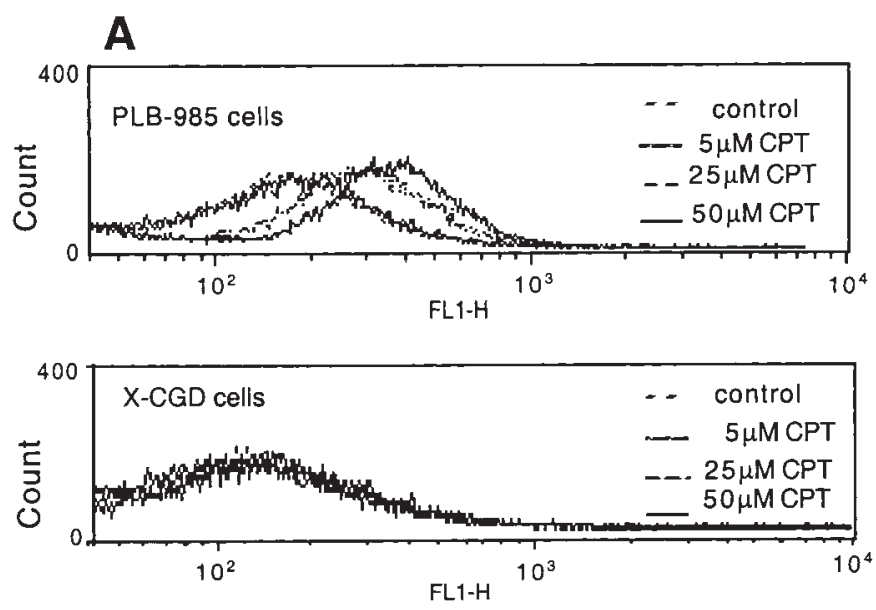

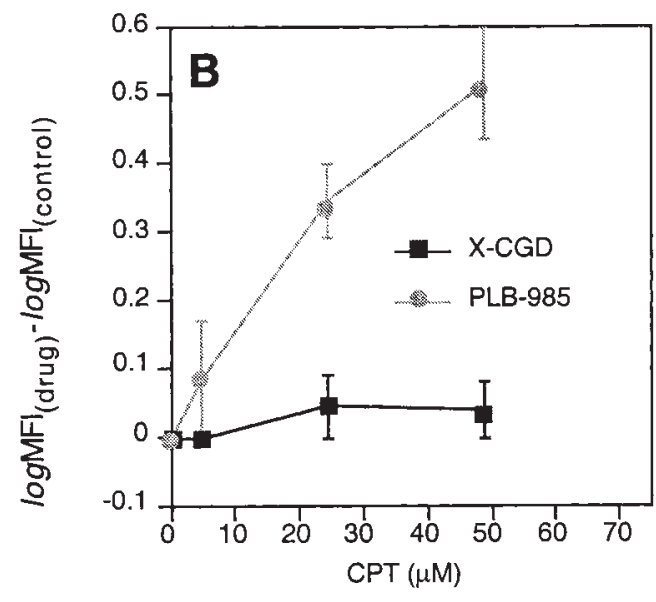

Figure 7. ROIs generation. Neutrophilic differentiated cells were preincubated with $5 \mu \mathrm{M} \mathrm{H}_{2} \mathrm{DCFHDA}$ for 30 min, before the addition of CPT. ROI levels were measured $1 \mathrm{~h}$ after CPT addition using a Becton Dickinson FACScan flow cytometer with excitation and emission settings of $488 \mathrm{~nm}$ and $530 \mathrm{~nm}$, respectively. The intensity of fluorescence of each sample was expressed as MFI calculated from each peak. $(A)$ Shift of fluorescence in granulocytic-differentiated PLB-985 cells and X-CGD cells. $(B)$ The extent of ROI production was computed as the difference $\left(\log M F I_{\text {drug }}-\log M F I_{\text {control }}\right)\left(M F I_{\text {drug }}\right.$, MFI of CPT-treated cells; $M F I_{\text {control }}$, MFI of control cells). Data are expressed as mean \pm SD obtained from at least three independent experiments.

985 cells is derived from activation of the NADPH oxidase system. Furthermore, the generation of ROIs is an immediate response to exposure to CPT and therefore occurs very early in apoptosis in CPT-treated PLB-985 cells.

\section{Discussion}

ROIs have been reported to be intermediates in signal transduction during apoptosis in hematopoietic cells $(2,4,5)$. In this paper, we investigated the role of the phagocyte NADPH oxidase in apoptosis in two human leukemia cells lines, X-CGD and PLB-985, which differ only by the inactivation of an essential component, gp91-phox in X-CGD. Specifically, we compared the effect of different inducers of apoptosis in the null cell line (X-CGD) and the parental cell line, PLB-985. Our data indicate that ROIs, generated by the NADPH oxidase, contribute to apoptosis induced by the top1 inhibitor, CPT in undifferentiated and granulocytic-differentiated PLB-985 cell lines. In addition, the top1 inhibitor CPT did not influence apoptosis in monocytic differentiated PLB-985 or X-CGD. In cells undifferentiated and differentiated into either lineage,
NADPH oxidase activity did not appear to be important for apoptosis in response to $\gamma$-ray, $\mathrm{UV}$ radiation, $\mathrm{H}_{2} \mathrm{O}_{2}, \mathrm{UCN}-01$, and VP-16. This is despite the reports that ROIs may participate directly or indirectly in cell death response to UV radiation or VP-16 (27, 30-33). One can surmise that other sources of ROIs, such as mitochondrial oxidase, might be related to UV- and VP-16-induced cell death.

Several antioxidants have been reported to effectively inhibit apoptosis $(31,34)$. In our study, PDTC partially protected PLB-985 cells from CPT-induced apoptosis. In addition to being an ROI scavenger, PDTC is an inhibitor of NF- $\mathrm{B}$ $(35,36)$. A relationship between the generation of ROIs and $\mathrm{NF}-\kappa \mathrm{B}$ activation has been suggested in ceramide-induced apoptosis (9). CPT-induced apoptosis was also inhibited by catalase, and this finding is consistent with the publication of Kawahara et al. (11) showing inhibition of spontaneous and CD95/apo-1-induced apoptosis by catalase in neutrophils. The observation that the oxygen radical scavengers, PDTC and catalase, each separately reduced DNA fragmentation in the parental cell line, PLB-985, to levels comparable with those of $\mathrm{X}-\mathrm{CGD}$ cells further supports a contribution of ROIs gener-

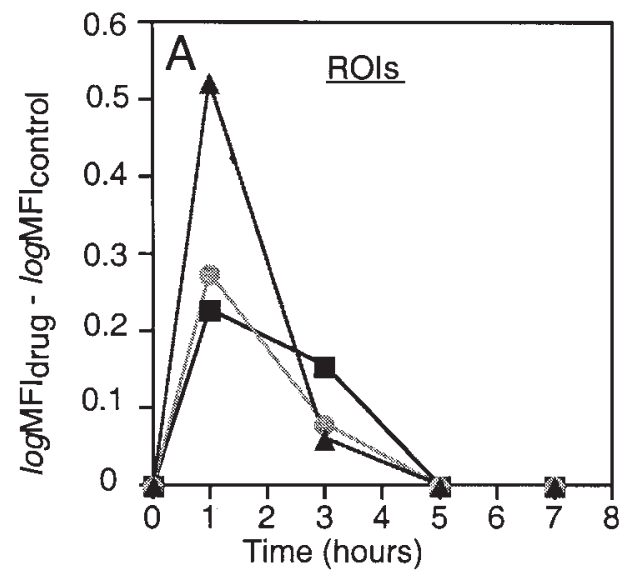

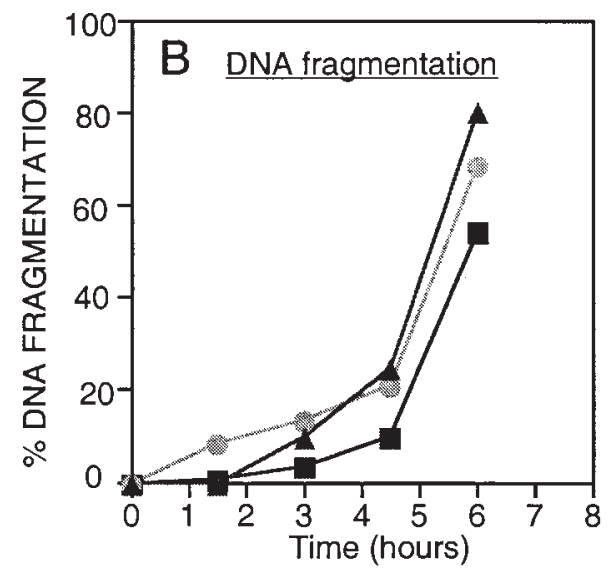

Figure 8. Time course of production of ROIs and DNA fragmentation in granulocytic-differentiated PLB985 cells treated with CPT. (A) Production of ROIs. Cells were treated with CPT for the indicated time periods before flow cytometry analysis. $\mathrm{H}_{2}$ DCFHDA was added $1.5 \mathrm{~h}$ prior to the measurements. $(B) \mathrm{Ki}$ netics of DNA fragmentation. (filled squares) $5 \mu \mathrm{M} \mathrm{CPT,} \mathrm{(gray}$ circles) $10 \mu \mathrm{M} \mathrm{CPT}$, (filled triangles) $50 \mu \mathrm{M} \mathrm{CPT}$. 
ated by NADPH oxidase in CPT-induced apoptosis in PLB985 cells.

The differential induction of apoptosis by CPT in granulocytic but not monocytic differentiated cells that are both capable of generating large quantities of ROIs is consistent with published studies in neutrophils isolated from individuals with chronic granulomatous disease (15). In particular, neutrophils from CGD patients are reported to be more resistant to spontaneous and Fas-induced apoptosis (11) compared with normal controls. Overexpression of Rac2 protein, which is a critical NADPH regulatory small GTP-binding protein, has been reported to enhance the induction of apoptosis in chimeric mice (37). Recently, components of the NADPH oxidase have been identified in nonphagocytic cells. It has been suggested that one or more components may contribute to signal transduction pathways important for oxygen sensing or vascular stability $(38,39)$. It is also possible that at least one component of the NADPH oxidase (or conceivably the entire enzyme) may contribute to the regulation of apoptosis in nonphagocytic cells.

The apoptotic response of X-CGD cells to a variety of DNA damaging agents and to UCN-01 and the observation that the apoptosis response of X-CGD cells was not affected by radical scavengers indicate the existence of an NADPH oxidase-independent apoptotic pathway. This pathway is prevalent for the X-CGD cells. It is probably also involved in the parental PLB985 cells because radical scavengers reduced CPT-induced DNA fragmentation to the levels observed in X-CGD cells. In addition, apoptotic DNA fragmentation was similarly induced in X-CGD and PLB-985 cells by UV radiation, $\mathrm{H}_{2} \mathrm{O}_{2}$, VP-16, or UCN-01. These observations indicate the importance of an NADPH oxidase-independent pathway for apoptosis in myeloblastic-derived cell lines.

CPT is a selective top1 poison (23), and its derivatives have recently been introduced in chemotherapy regimens for colon and ovarian carcinomas (40-42). CPTs poison eukaryotic top1 by trapping the enzyme catalytic intermediates: the cleavage (or cleavable) complexes $(43,44)$. The cytotoxicity of CPT requires that the cleavage complexes be converted into DNA damage (23). Until recently, it was assumed that the collision of replication forks into the CPT-trapped cleavage complexes was the main factor for CPT-induced cytotoxicity (23). This conclusion was based on the observation that pharmacological stalling of DNA replication abrogated CPT cytotoxicity and that the cytotoxicity of CPT appeared S-phase dependent. More recently, a DNA replication-independent component has emerged for CPT cytotoxicity $(45,46)$. The present observation that differentiated cells remained sensitive to CPT-induced apoptosis further argues that CPT-induced DNA damage and cell death can be initiated by nonreplicative processes such as transcription (47).

\section{Acknowledgments}

We gratefully acknowledge Dr. Kurt W. Kohn for helpful discussion. We would also like to thank Dr. Noriko Takahashi for technical advice.

\section{References}

1. Peter, M.E., A.E. Heufelder, and M.O. Hengartner. 1997. Advances in apoptosis research. Proc. Natl. Acad. Sci. USA. 94:12736-12737.

2. Feng, L., Y. Xia, G.E. Garcia, D. Hwang, and C.B. Wilson. 1995. Involvement of reactive oxygen intermediates in cyclooxygenase-2 expression induced by interleukin-1, tumor necrosis factor-alpha, and lipopolysaccharide. J. Clin.
Invest. 95:1669-1675.

3. Huang, R.P., J.X. Wu, Y. Fan, and E.D. Adamson. 1996. UV activates growth factor receptors via reactive oxygen intermediates. J. Cell Biol. 133:211220

4. Los, M., H. Schenk, K. Hexel, P.A. Baeuerle, W. Droge, and K. SchulzeOsthoff. 1995. IL-2 gene expression and NF-kappa B activation through CD28 requires reactive oxygen production by 5-lipoxygenase. EMBO (Eur. Mol. Biol. Organ.) J. 14:3731-3740.

5. Yan, S.R., and G. Berton. 1996. Regulation of Src family tyrosine kinase activities in adherent human neutrophils. Evidence that reactive oxygen intermediates produced by adherent neutrophils increase the activity of the p58c-fgr and p53/56lyn tyrosine kinases. J. Biol. Chem. 271:23464-23471.

6. Halliwell, B., and J.M.C. Gutteridge. 1989. Free Radicals in Biology and Medicine. Clarendon Press, Oxford.

7. Schulze-Osthoff, K., A.C. Bakker, B. Vanhaesebroeck, R. Beyaert, W.A. Jacob, and W. Fiers. 1992. Cytotoxic activity of tumor necrosis factor is mediated by early damage of mitochondrial functions. Evidence for the involvement of mitochondrial radical generation. J. Biol. Chem. 267:5317-5323.

8. Wang, J.F., T.R. Jerrells, and J.J. Spitzer. 1996. Decreased production of reactive oxygen intermediates is an early event during in vitro apoptosis of rat thymocytes. Free Radic. Biol. Med. 20:533-542.

9. Quillet-Mary, A., J.P. Jaffrezou, V. Mansat, C. Bordier, J. Naval, and G. Laurent. 1997. Implication of mitochondrial hydrogen peroxide generation in ceramide-induced apoptosis. J. Biol. Chem. 272:21388-21395.

10. Bogdanov, K.V., A.B. Chukhlovin, A.Y. Zaritskey, O.I. Frolova, and B.V. Afanasiev. 1997. Ultraviolet irradiation induces multiple DNA doublestrand breaks and apoptosis in normal granulocytes and chronic myeloid leukaemia blasts. Br. J. Haematol. 98:869-872

11. Kasahara, Y., K. Iwai, A. Yachie, K. Ohta, A. Konno, H. Seki, T. Miyawaki, and N. Taniguchi. 1997. Involvement of reactive oxygen intermediates in spontaneous and CD95 (Fas/APO-1)-mediated apoptosis of neutrophils. Blood. 89:1748-1753.

12. Morel, F., J. Doussiere, and P.V. Vignais. 1991. The superoxide-generating oxidase of phagocytic cells. Physiological, molecular and pathological aspects. Eur. J. Biochem. 201:523-546.

13. Dinauer, M.C. 1993. The respiratory burst oxidase and the molecular genetics of chronic granulomatous disease. Crit. Rev. Clin. Lab. Sci. 30:329-369.

14. Chanock, S.J., J. el Benna, R.M. Smith, and B.M. Babior. 1994. The respiratory burst oxidase. J. Biol. Chem. 269:24519-24522.

15. Roos, D., M. de Boer, F. Kuribayashi, C. Meischl, R.S. Weening, A.W. Segal, A. Ahlin, K. Nemet, J.P. Hossle, E. Bernatowska-Matuszkiewicz, et al. 1996. Mutations in the X-linked and autosomal recessive forms of chronic granulomatous disease. Blood. 87:1663-1681.

16. Quinn, M.T., T. Evans, L.R. Loetterle, A.J. Jesaitis, and G.M. Bokoch. 1993. Translocation of Rac correlates with NADPH oxidase activation. Evidence for equimolar translocation of oxidase components. J. Biol. Chem. 268: 20983-20987.

17. el Benna, J., J.M. Ruedi, and B.M. Babior. 1994. Cytosolic guanine nucleotide-binding protein Rac2 operates in vivo as a component of the neutrophil respiratory burst oxidase. Transfer of Rac2 and the cytosolic oxidase components p47phox and p67phox to the submembranous actin cytoskeleton during oxidase activation. J. Biol. Chem. 269:6729-6234.

18. Zhen, L., A.A. King, Y. Xiao, S.J. Chanock, S.H. Orkin, and M.C. Dinauer. 1993. Gene targeting of X chromosome-linked chronic granulomatous disease locus in a human myeloid leukemia cell line and rescue by expression of recombinant gp91phox. Proc. Natl. Acad. Sci. USA. 90:9832-9836.

19. Yu, L., L. Zhen, and M.C. Dinauer. 1997. Biosynthesis of the phagocyte NADPH oxidase cytochrome b558. Role of heme incorporation and heterodimer formation in maturation and stability of gp91phox and $\mathrm{p} 22 \mathrm{phox}$ subunits. J. Biol. Chem. 272:27288-27294.

20. Shao, R.G., C.X. Cao, and Y. Pommier. 1997. Activation of PKC alpha downstream from caspases during apoptosis induced by 7-hydroxystaurosporine or the topoisomerase inhibitors, camptothecin and etoposide, in human myeloid leukemia HL60 cells. J. Biol. Chem. 272:31321-31325.

21. Shao, R.G., T. Shimizu, and Y. Pommier. 1997. 7-Hydroxystaurosporine (UCN-01) induces apoptosis in human colon carcinoma and leukemia cells independently of p53. Exp. Cell. Res. 234:388-397.

22. Akinaga, S., K. Gomi, M. Morimoto, T. Tamaoki, and M. Okabe. 1991. Antitumor activity of UCN-01, a selective inhibitor of protein kinase C, in murine and human tumor models. Cancer Res. 51:4888-4892.

23. Pommier, Y. 1996. Eukaryotic DNA topoisomerase I: genome gatekeeper and its intruders, camptothecins. Semin. Oncol. 23 (Suppl 3):3-10.

24. Bertrand, R., M. Sarang, J. Jenkin, D. Kerrigan, and Y. Pommier. 1991. Differential induction of secondary DNA fragmentation by topoisomerase II inhibitors in human tumor cell lines with amplified c-myc expression. Cancer Res. 51:6280-6285.

25. Bertrand, R., K.W. Kohn, E. Solary, and Y. Pommier. 1995. Detection of apoptosis-associated DNA fragmentation using a rapid and quantitative filter elution assay. Drug Dev. Res. 34:138-144.

26. Shimizu, T., P.M. O'Connor, K.W. Kohn, and Y. Pommier. 1995. Unscheduled activation of cyclin B1/Cdc2 kinase in human promyelocytic leukemia cell line HL60 cells undergoing apoptosis induced by DNA damage. Cancer 
Res. 55:228-231.

27. Gorman, A., A. McGowan, and T.G. Cotter. 1997. Role of peroxide and superoxide anion during tumour cell apoptosis. FEBS Lett. 404:27-33.

28. Bertrand, R., and Y. Pommier. 1995. Assessment of DNA damage in mammalian cells by DNA filtration methods. In Cell Growth and Apoptosis: A Practical Approach. G. Studzinski, editor. IRL Press, Oxford University Press, Oxford. 96-117.

29. Goldwasser, F., I. Bae, M. Valenti, K. Torres, and Y. Pommier. 1995. Topoisomerase I-related parameters and camptothecin activity in the colon carcinoma cell lines from the National Cancer Institute anticancer screen. Cancer Res. 55:2116-2121.

30. Fernandes, R.S., A.J. McGowan, and T.G. Cotter. 1996. Mutant H-ras overexpression inhibits drug and U.V. induced apoptosis. Anticancer Res. 16: 1691-1705.

31. Bustamante, J., A.F. Slater, and S. Orrenius. 1995. Antioxidant inhibition of thymocyte apoptosis by dihydrolipoic acid. Free Radic. Biol. Med. 19:339-347.

32. Kanatate, T., N. Nagao, M. Sugimoto, K. Kageyama, T. Fujimoto, and N. Miwa. 1995. Differential susceptibility of epidermal keratinocytes and neuroblastoma cells to cytotoxicity of ultraviolet-B light irradiation prevented by the oxygen radical-scavenger ascorbate-2-phosphate but not by ascorbate. Cell. Mol. Biol. Res. 41:561-567.

33. Pourzand, C., G. Rossier, O. Reelfs, C. Borner, and R.M. Tyrrell. 1997. Overexpression of Bcl-2 inhibits UVA-mediated immediate apoptosis in rat 6 fibroblasts: evidence for the involvement of $\mathrm{Bcl}-2$ as an antioxidant. Cancer Res. 57:1405-1411.

34. Briehl, M.M., A.F. Baker, L.M. Siemankowski, and J. Morreale. 1997. Modulation of antioxidant defenses during apoptosis. Oncol. Res. 9:281-285.

35. Lin, K.I., S.H. Lee, R. Narayanan, J.M. Baraban, J.M. Hardwick, and R.R. Ratan. 1995. Thiol agents and Bcl-2 identify an alphavirus-induced apoptotic pathway that requires activation of the transcription factor NF-kappa B. $J$. Cell Biol. 131:1149-1161.

36. Lee, R., P. Beauparlant, H. Elford, P. Ponka, and J. Hiscott. 1997. Selective inhibition of $1 \mathrm{kappaB}$ alpha phosphorylation and HIV-1 LTR-directed gene expression by novel antioxidant compounds. Virology. 234:277-290.
37. Lores, P., L. Morin, R. Luna, and G. Gacon. 1997. Enhanced apoptosis in the thymus of transgenic mice expressing constitutively activated forms of human Rac2GTPase. Oncogene. 15:601-605.

38. Wenger, R.H., H.H. Marti, C.C. Schuerer-Maly, I. Kvietikova, C. Bauer, M. Gassmann, and F.E. Maly. 1996. Hypoxic induction of gene expression in chronic granulomatous disease-derived B-cell lines: oxygen sensing is independent of the cytochrome b558-containing nicotinamide adenine dinucleotide phosphate oxidase. Blood. 87:756-761.

39. Fukui, T. N. Ishizaka, S. Rajagopalan, J.B. Laursen, Q.T. Capers, W.R. Taylor, D.G. Harrison, H. de Leon, J.N. Wilcox, and K.K. Griendling. 1997. p22phox mRNA expression and NADPH oxidase activity are increased in aortas from hypertensive rats. Circ. Res. 80:45-51.

40. Dancey, J., and E.A. Eisenhauer. 1996. Current perspectives on camptothecins in cancer treatment [editorial]. Br. J. Cancer. 74:327-338.

41. Slichenmyer, W.J., E.K. Rowinsky, R.C. Donehower, and S.H. Kaufmann. 1993. The current status of camptothecin analogues as antitumor agents. J. Natl. Cancer Inst. 85:271-291.

42. Potmesil, M. 1994. Camptothecins: from bench research to hospital wards. Cancer Res. 54:1431-1439.

43. Wang, J.C., P.R. Caron, and R.A. Kim. 1990. The role of DNA topoisomerases in recombination and genome stability: a double-edged sword? Cell. 62:403-406.

44. Gupta, M., A. Fujimori, and Y. Pommier. 1995. Eukaryotic DNA topoisomerases I. Biochim. Biophys. Acta. 1262:1-14.

45. Goldwasser, F., T. Shimizu, J. Jackman, Y. Hoki, P.M. O'Connor, K.W. Kohn, and Y. Pommier. 1996. Correlations between S and G2 arrest and the cytotoxicity of camptothecin in human colon carcinoma cells. Cancer Res. 56: 4430-4437.

46. Morris, E.J., and H.M. Geller. 1996. Induction of neuronal apoptosis by camptothecin, an inhibitor of DNA topoisomerase-I: evidence for cell cycleindependent toxicity. J. Cell Biol. 134:757-770.

47. Wu, J., and L.F. Liu. 1997. Processing of topoisomerase I cleavable complexes into DNA damage by transcription. Nucleic Acids Res. 25:4181-4186. 